\title{
Novel Perspectives in Redox Biology and Pathophysiology of Failing Myocytes: Modulation of the Intramyocardial Redox Milieu for Therapeutic Interventions-A Review Article from the Working Group of Cardiac Cell Biology, Italian Society of Cardiology
}

\author{
Alessia Arcaro, ${ }^{1}$ Flora Pirozzi, ${ }^{2}$ Annalisa Angelini, ${ }^{3}$ Cristina Chimenti, ${ }^{4}$ Lia Crotti, ${ }^{5,6}$ \\ Carla Giordano, ${ }^{7}$ Daniele Mancardi, ${ }^{8}$ Daniele Torella, ${ }^{9}$ and Carlo G. Tocchetti ${ }^{2}$ \\ ${ }^{1}$ Department of Medicine and Health Sciences, University of Molise, 86100 Campobasso, Italy \\ ${ }^{2}$ Department of Translational Medical Sciences, Division of Internal Medicine, Federico II University, 80131 Naples, Italy \\ ${ }^{3}$ Cardiovascular Pathology Unit, Department of Thoracic, Cardiac and Vascular Sciences, University of Padova, 35121 Padova, Italy \\ ${ }^{4}$ La Sapienza University and IRCCS L. Spallanzani, 00161 Rome, Italy \\ ${ }^{5}$ Department of Molecular Medicine, University of Pavia, 27100 Pavia, Italy \\ ${ }^{6}$ Center for Cardiac Arrhythmias of Genetic Origin, IRCCS Istituto Auxologico Italiano, 20135 Milano, Italy \\ ${ }^{7}$ Department of Radiological, Oncological and Anatomo-Pathological Sciences, La Sapienza University, 00161 Rome, Italy \\ ${ }^{8}$ Department of Clinical and Biological Sciences, University of Torino, 10043 Orbassano, Italy \\ ${ }^{9}$ Molecular and Cellular Cardiology, Department of Medical and Surgical Sciences, Magna Graecia University, 88100 Catanzaro, Italy \\ Correspondence should be addressed to Carlo G. Tocchetti; carlogabriele.tocchetti@unina.it
}

Received 4 July 2015; Accepted 16 November 2015

Academic Editor: Gerasimos Sykiotis

Copyright (C) 2016 Alessia Arcaro et al. This is an open access article distributed under the Creative Commons Attribution License, which permits unrestricted use, distribution, and reproduction in any medium, provided the original work is properly cited.

\begin{abstract}
The prevalence of heart failure (HF) is still increasing worldwide, with enormous human, social, and economic costs, in spite of huge efforts in understanding pathogenetic mechanisms and in developing effective therapies that have transformed this syndrome into a chronic disease. Myocardial redox imbalance is a hallmark of this syndrome, since excessive reactive oxygen and nitrogen species can behave as signaling molecules in the pathogenesis of hypertrophy and heart failure, leading to dysregulation of cellular calcium handling, of the contractile machinery, of myocardial energetics and metabolism, and of extracellular matrix deposition. Recently, following new interesting advances in understanding myocardial ROS and RNS signaling pathways, new promising therapeutical approaches with antioxidant properties are being developed, keeping in mind that scavenging ROS and RNS tout court is detrimental as well, since these molecules also play a role in physiological myocardial homeostasis.
\end{abstract}

\section{Introduction}

The prevalence of heart failure (HF) is still increasing worldwide, with enormous human, social, and economic costs [1-6], despite huge efforts in understanding pathogenetic mechanisms and in developing effective therapies that have transformed this syndrome into a chronic disease. Recently, following new interesting advances in understanding intracellular signaling pathways that control the main altered processes in the failing heart (such as cellular calcium handling and the contractile machinery, cardiac hypertrophy and dilatation, and myocardial energetics and metabolism), new promising therapeutical approaches are being developed. It is well established that cardiomyocytes of a failing heart are redox imbalanced, and, in this paper, we review and discuss the pathophysiology of HF, keeping in mind that ROS and RNS play an important role as signaling molecules in physiological myocardial homeostasis. 


\section{Heart Failure as a Systemic Disease}

The etiology of heart dysfunction is heterogeneous, although individuals with $\mathrm{HF}$ have rather common symptoms as fatigue, shortness of breath, and fluid retention. Half of HF patients present with contractile failure and a dilated heart (systolic HF), while other patients have normal systolic function with a preserved ejection fraction (EF) and a nondilated, but often hypertrophied, heart. This latter is also named HF with preserved ejection fraction (HFpEF) [7].

Central to the pathogenesis of systolic HF is decreased left ventricular (LV) contractile function, due to an initial ischaemic insult (e.g., myocardial infarction, MI) or to nonischaemic insult (including genetic and inflammatory cardiomyopathies, hypertension, metabolic diseases, or toxic injury). These insults induce an inexorable series of compensatory responses in the body, including the retention of salt and water by the kidneys, the release of neurohormones, and the activation of intracellular signaling cascades in the heart and vasculature that modify cellular and organ morphology and function. Such responses initially offset reduced cardiac performance but then become part of the disease process, increasing organ failure and worsening clinical prognosis [17].

\section{Neurohumoral Adaptations}

When cardiac contractile dysfunction is established, the body responds by increasing release of sympathetic neurotransmitters, adrenaline and noradrenaline, and neurohormones, including angiotensin II (ATII), endothelin, and natriuretic peptides. These events contribute to maintaining cardiac output, increasing rate and intensity of heart contraction, and fluid retention. Such chronic stimulation becomes adverse and worsens prognosis of heart failure [8]. Indeed, current HF therapies mainly rely on antagonizing such neurohumoral activated pathways with $\beta$-adrenergic and angiotensin receptor blockade and angiotensin converting enzyme (ACE) inhibition and on hemodynamic control with nitrates and diuretics, with the net effect of producing vasodilation and lowering blood pressure, therefore unloading the heart [1-7]. Therapies based on blockade of $\beta$-adrenergic receptors $(\beta$ ARs), inhibition of angiotensin converting enzyme, blockade of the angiotensin II receptor AT1, and blockade of aldosterone receptor improved survival and symptoms in heart failure patients $[1,7,9-11]$.

\section{Energetic Breakdown in Heart Failure}

The heart is an organ with limited capacity for storing energy. Thereby, to supply its high and constant workload, it needs substrates produced quickly and efficiently, mainly from circulating fatty acids (FA) rather than from glucose. A failing heart enters a state of inefficiency and of energy starvation, mainly due to a compromised regulation of energy metabolism, a reduced ATP availability, or an altered substrates utilization $[7,12]$.

A shift in energy metabolism from normal using of fatty acids (due to a decline in the expression of genes involved in fatty acid metabolism [13]) towards using glucose, which probably results in differences in substrates oxidation and thus mitochondrial function, has been observed in both ischaemic and nonischaemic heart failure [13-16]. Therefore, with this shift of metabolic profile, the myocardium relies on glycolysis for ATP generation [17, 18]. This situation has important fallouts in specific conditions such as heart failure associated with diabetes [19]. In this case, reduced FA oxidation is not accompanied by an increase in glucose or lactate oxidation to provide ATP, thus causing an energetic deficit in the failing heart that correlates with overall disease severity $[13,18]$. Importantly, in diabetes, hyperglycemia per se, independently of FA utilization, is able to lead to cellular derangements and to adaptive and maladaptive processes involving, among many, the renin-angiotensinaldosterone system, glucose transporters, and AGEs [20, 21]. In this setting, mitochondrial failure to generate enough ATP, coupled to increased ROS generation, with consequent ROS-induced posttranslational modifications of important proteins of the EC coupling machinery is directly involved in diabetic cardiomyopathy $[21,22]$.

In a failing heart not only ATP synthesis but also ATP storage is altered. Phosphocreatine is ATP storage molecule, which, in presence of ADP, is converted to creatine and ATP by creatine kinase, thereby generating rapidly energy when it is needed. The ratio of concentrations of phosphocreatine to ATP is used as a measure of energy balance. This ratio is found abnormal in heart failure together with the ATP flux [23].

\section{Oxidative Stress and Heart Failure}

Oxidative stress is commonly referred to as unbalanced ratio between production and scavenging of oxygen radicals with a detrimental oxidation of different substrates (proteins, lipids, nucleic acids, and others). The onset of a prooxidative condition can be due to a hyperactivation of different reactive species sources (see below) or to a depletion of antioxidant defenses or both. It is not clear whether oxidative stress is to be considered a cause, an index, or a mediator of heart failure. In the next paragraphs the sources and effects of prooxidant will be described in order to elucidate the role of oxygen radicals on the etiopathology of a failing heart (Figure 1).

\section{Sources of Reactive Oxygen and Nitrogen Species in Heart Failure}

Both excessive neurohormonal stimulation and energetic deficits with mitochondrial dysfunction lead to increased oxidative stress $[21,24]$ with production of excessive Reactive Oxygen Species (ROS) and Reactive Nitrogen Species (RNS), widely recognized as promotors of both cardiac dysfunction and pathological remodeling of $\mathrm{HF}$, which is characterized by altered excitation-contraction (EC) coupling with abnormally lower cardiac contractility and muscle relaxation velocities. Among other events linked to HF onset and progression are maladaptive hypertrophic myocardial response, extracellular matrix remodeling, altered tissue energetics, 


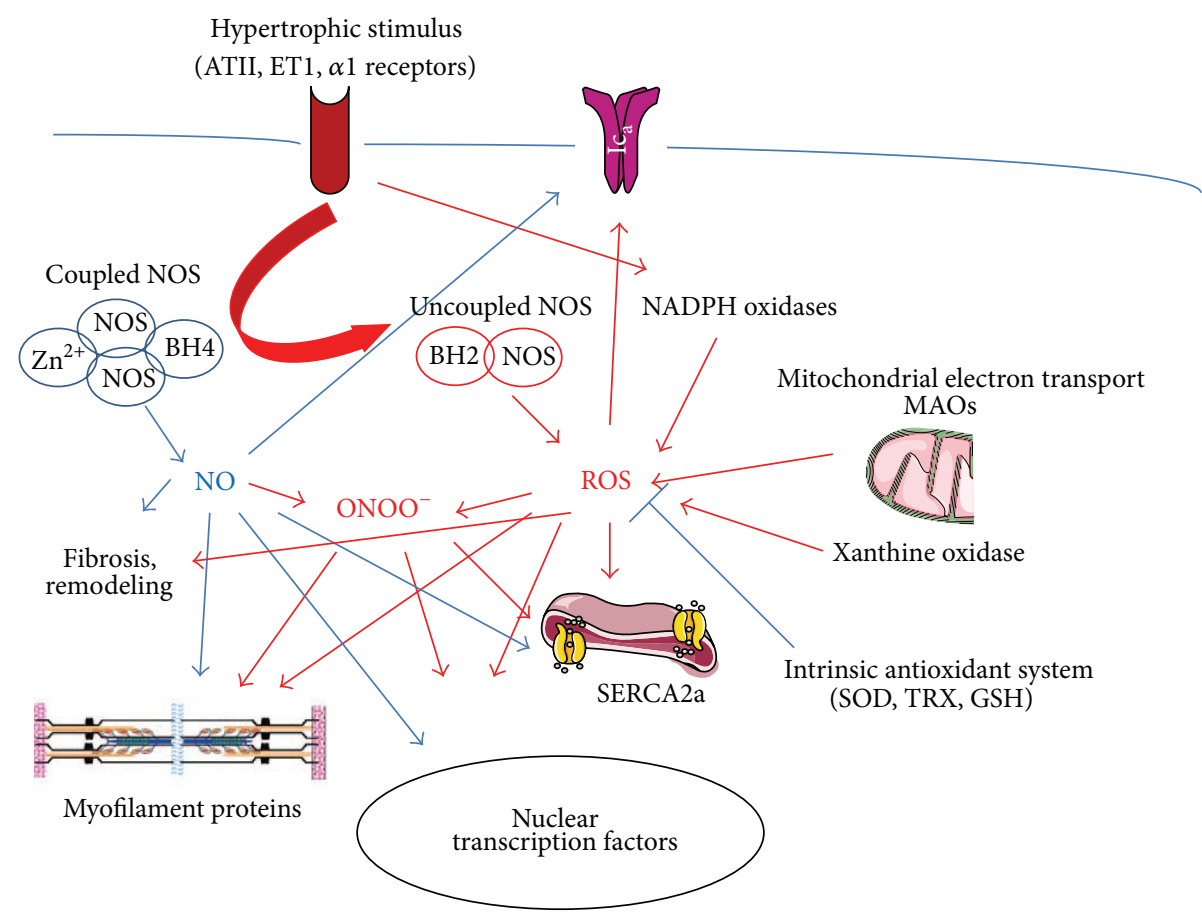

FIGURE 1: ROS promote heart failure by many mechanisms. Some of the deleterious effects of ROS are evidenced by red arrows. NO counteracts such effects (blue arrows). Modified from Tocchetti et al. [25].

loss of viable cardiomyocytes, vascular and capillary abnormalities, and inflammation [4, 7, 25-30]. Myocardial redox imbalance may be responsible, at least in part, for such abnormalities [22, 31]. ROS and RNS can be produced endogenously by cardiomyocytes by several cellular sources, including "direct" production such as NADPH oxidase system, lipoxygenases, cyclooxygenases, peroxidases, mitochondrial oxidative phosphorylation, nitric-oxide synthase 3 (NOS3 or eNOS) [25-27, 32-34] and "indirect" (free radicals production inducers) such as cytokines, growth factors, angiotensin II, catecholamines, pressure overload, xanthine oxidases, monoamine oxidases, enzymes of catecholamine and serotonin catabolism. Also, the myocardium is provided with endogenous nonenzymatic (i.e., glutathione, vitamins $\mathrm{E}$ and $\mathrm{C}$, and $\beta$-carotene [33], lipoic acid, ubiquinone, and urate) and enzymatic systems that catabolize ROS physiologically generated [25].

NADPH oxidases are important cellular sources of ROS, crucial in many pathophysiological conditions that lead to cardiac diseases [25, 35-37]. The NADPH oxidase enzyme complex is composed of seven catalytic subunits, Nox1-Nox5 and Duox1 and Duox2. Nox2 and Nox4 are expressed in the heart and produce ROS by electron transfer from NADPH to molecular oxygen. In physiological states, Nox2 is quiescent and is stimulated by the translocation of regulatory proteins to activate the oxidase complex on the membrane $[25,38]$. G-protein-coupled receptor agonists, cytokines, and growth factors can stimulate Nox2 to generate ROS. On the other hand, Nox4 is constitutively active and is modulated by its expression levels [25, 37]. Both Nox2 and Nox4 are key players in the pathogenesis of LV dysfunction. Indeed, after myocardial infarction, myocytes hypertrophy and apoptosis were significantly reduced in aortic rings of Nox2-deficient mice, with less LV dilation and better function compared to wild type mice $[25,37,39]$. Also, Nox2-containing NADPH oxidases play a role in ATII-induced hypertrophy independently of pressure overload [37]. The underlying mechanism at the base of the prohypertrophic Nox2 effect relies, at least in part, on the oxidation of mitochondrial proteins induced by increased production $\mathrm{O}_{2}{ }^{-}$that leads to mitochondrial dysfunction [39]. At the same time, Nox4-containing NADPH oxidases are important in the pathophysiology of cardiac hypertrophy from pressure overload: pressure overloaded hearts from c-Nox $4^{-/-}$mice showed less hypertrophy and less interstitial fibrosis and apoptosis and had improved LV function compared to wild type $[25,37,40]$. Human failing hearts exhibit increased NADPH oxidase activation [41] together with the parallel activation of downstream signaling components ERK1/2, JNK, and p38 [42]. Also, Nox4 levels increase gradually in aging cardiomyocytes; interestingly, apoptosis is also increased upon enhanced Nox4 expression of caused apoptosis [25,37]. Nox4 appears to produce mostly $\mathrm{H}_{2} \mathrm{O}_{2}$, while Nox2 generates mostly $\mathrm{O}_{2}{ }^{-}[35,36]$.

ROS can be also produced by xanthine oxidase (XO), an enzyme that belongs to the molybdoenzyme family (which comprises enzymes such as aldehyde oxidase and sulfite oxidase) [43]. Both $\mathrm{O}^{2-}$ and $\mathrm{H}_{2} \mathrm{O}_{2} \mathrm{XO}$ can be generated by oxidative hydroxylation of purine substrates from XO. Inhibition of xanthine oxidoreductase improves cardiac structure and function in spontaneously hypertensive/HF rats $[25,44]$. Also, XO can be activated by $\mathrm{NAD}(\mathrm{P}) \mathrm{H}$ oxidase $[25,45]$. Compared to wild type animals, myocardial $\mathrm{XO}$ activity 
did not increase after MI in p47phox-/- mice (genetically deprived of p47phox, the cytosolic NADPH oxidase component). Disappointingly, XO inhibitors, such as the purine analog allopurinol and the nonpurine analog febuxostat, when employed clinically, did not exert beneficial effects on human ischaemia/reperfusion and cardiac dysfunction [25], in spite of some success in animal studies [46-48]. Indeed, xanthine oxidase importance and role in the human heart have been questioned [49].

Because of their high-energy needs, cardiac myocytes possess a large number of mitochondria that not only can produce ATP but also can generate ROS as a by-product of mitochondrial respiration. Mitochondrial ROS are produced because the transfer of electrons via the electron transport chain is not totally efficient [50], with $\mathrm{O}_{2}{ }^{-}$being generated in the mitochondria at a measurable rate during physiological oxidative phosphorylation. Most of mitochondrial $\mathrm{O}_{2}{ }^{-}$ possesses a relatively short half-life [43]. In the mitochondria, manganese superoxide dismutase (SOD) is located in matrix while copper/zinc SOD is in the intermembrane space: both of these enzymes can transform $\mathrm{O}_{2}^{-}$into $\mathrm{H}_{2} \mathrm{O}_{2}$, that is not so reactive as $\mathrm{O}_{2}{ }^{-}$and can easily diffuse and behave as signaling molecule [51]. An alternative enzymatic reaction is operated by other antioxidant enzymes, such as glutathione peroxidase- 1 and catalase, which can convert $\mathrm{H}_{2} \mathrm{O}_{2}$ to $\mathrm{O}_{2}$ and $\mathrm{H}_{2} \mathrm{O}$ [50]. Nevertheless, an imbalance between mitochondrial prooxidant and antioxidant systems can bring to mitochondrial oxidative stress. Differently from $\mathrm{H}_{2} \mathrm{O}_{2}$, $\mathrm{OH}$ (hydroxyl radical) cannot be catabolized by enzymatic reactions but can be quenched only by endogenous or food antioxidants. $\mathrm{OH}$ possesses a very short half-life and is very reactive in vivo; therefore it is believed to be a very dangerous molecule [52]. $\mathrm{OH}$ is a player in reperfusion injury, in HF, stroke, and $\mathrm{MI}$, and in $\mathrm{Ca}^{2+}$ cycling and myofilament $\mathrm{Ca}^{2+}$ sensitivity in experimental myocardial preparations $[33,53]$.

Mitochondria produce more ROS during stress conditions, among many ischaemia/reperfusion and cardiac dysfunction [43,54-56]. ROS can be generated not only on the inner mitochondrial membrane, but also on the outer mitochondrial membrane thanks to monoamine oxidases (MAOs) $\mathrm{A}$ and $\mathrm{B}$ during oxidative deamination of catecholamines and serotonin [57] (Figure 1).

\section{Antioxidant Defenses}

Antioxidants can be mainly divided into 2 groups: exogenous and endogenous. Antioxidants from exogenous sources are normally introduced with the diet and include (but are not limited to) vitamins (A and C), carotenoids, and flavonoids $[58,59]$. On the other hand, endogenous compounds with antioxidant properties can be either of enzymatic origin (superoxide dismutase, GPx, and catalase) or nonenzymatic antioxidants (vitamin E, GSH, and bilirubin) [33]. The therapeutic approach to HF aimed at reducing oxidative stress would benefit from reducing radicals production and by enhancing antioxidant defenses reducing the ratio between the two.

\section{The Double-Edged Role of Nitric-Oxide Synthases in Cardiac Dysfunction}

Nitric-oxide synthases (NOSs) are extremely interesting molecules that produce NO by oxidizing the terminal guanidine nitrogen of L-arginine to L-citrulline. NOSs are present in 3 isoforms [43]: endothelial NOS3 (eNOS) and neuronal NOS1 (nNOS) are constitutively expressed in cardiomyocytes, while inducible NOS2 (iNOS) is absent in the normal myocardium, but its expression can be induced by proinflammatory mediators [25, 60-63]. NO is able to have diverse biological effects by posttranslational nitrosation/nitrosylation of specific cysteine thiol residues [43], mostly due to the cellular location in which NO is generated $[28,64]$. NOS3 is mainly located into sarcolemmal caveolae and $\mathrm{t}$ tubules, where it interacts with caveolin-3 that modulates its activity and is connected with many cell surface receptors and $\beta$ adrenergic and bradykinin receptors $[43,65,66]$. NOS3generated NO has a key role in depressing contractility and regulating $\beta$-adrenergic stimulation. On the opposite, NOS1 is usually described in the sarcoplasmic reticulum and coimmunoprecipitates with ryanodine receptors (RyRs), thus increasing contractility without altering ICa $[25,28,61]$. Hence, in contrast to NOS3, it appears that NOS1 has mainly a positive inotropic effect on the myocardium [43, 61].

Importantly, $\mathrm{NO}$ also plays an essential role in the maintenance of the $\mathrm{O}_{2}{ }^{-} / \mathrm{NO}$ homeostasis and can inhibit $\mathrm{XO}$, thus behaving as an antioxidant $[25,67,68]$. In cardiac pathophysiology, maintenance of the nitroso/redox balance between RNS and ROS is critical [25, 27], since excessive oxidative and nitrosative stress are pivotal in many deleterious effects on the myocardium. Indeed, oxidative/nitrosative stress mediate cellular damage to organelles, DNA, proteins, lipids, and other macromolecules and can ultimately bring cardiomyocyte death [29]. Oxidative stress occurs when intrinsic antioxidant defenses are not able to protect from excessive ROS production.

Interestingly, in some pathological conditions, including HF, NOS can be uncoupled, and hence the flow of electrons from the reductase domain to the heme can be diverted to molecular oxygen instead of L-arginine, with following $\mathrm{O}_{2}{ }^{-}$ production $[69,70]$. Among the mechanisms that may be responsible for NOS3 uncoupling, tetrahydrobiopterin (BH4, a fundamental cofactor of NOS) deficiency has been often described [71-73]. Additionally, excessive ROS can further exacerbate NOS uncoupling [25]. NO generated by NOSs is able to react and interact with ROS. Indeed, in HF, ROS and RNS generated by different sources can decrease NO bioavailability. Such interactions can have a significant effect on myocardial contractility [33]. In failing hearts, beyond lower antioxidant defenses, diminished NO levels can bring a further increase in ROS because of NOS uncoupling [64] (Figure 1). Of notice, ROS such as superoxide can directly quench bioavailable NO even without affecting the expression and activity of NOS [74]. Superoxide anion $\left(\mathrm{O}_{2}^{-}\right)$can react with $\mathrm{NO}$, forming reactive species such as peroxynitrite, producing abnormalities in the nitroso-redox balance and further myocardial derangements $[26,30]$. Importantly, in cardiomyocytes NO mediates S-nitrosylation of specific 
cysteines [33,75], with effects on $\mathrm{Ca}^{2+}$ fluxes and EC coupling $[33,76]$, but high levels of $\mathrm{O}_{2}^{-}$can inhibit physiologic Snitrosylation. High $\mathrm{O}_{2}{ }^{-}$concentrations interact with $\mathrm{NO}$ to form peroxynitrite that can produce numerous cytotoxic effects that may alter excitation-contraction coupling [26, $77,78]$. Additionally, in failing myocytes, NOS1 moves from its sarcoplasmic reticulum (SR) subcellular location to the sarcolemmal membrane $[43,79]$, disrupting the tight timeand substrate-dependent NOS regulation. Also, the high levels of NOS2 in failing myocytes appear to be, at least in part, a cause of the blunted myocardial inotropy after $\beta$ adrenergic stimulation $[80,81]$.

\section{ROS-Mediated Alterations in Cardiac Dysfunction}

In the heart, ROS stimulate transcription factors to promote hypertrophic signaling, therefore producing cardiac growth, remodeling, and dysfunction. ROS affect cardiac contractility and survival $[4,7,25-30]$. Cardiomyocytes apoptosis that is present in hypertrophy and HF contributes to development and progression of cardiac dysfunction [33, 82]. High levels of ROS have a key role in myocytes apoptosis. Indeed, at relatively low levels, ROS stimulates protein synthesis, while, at higher levels, there is activation of JNK and p38 MAPKs and Akt and induction of apoptosis [33]. Interestingly, in rat cardiomyocytes, $\mathrm{H}_{2} \mathrm{O}_{2}$ at low micromolar concentrations blunts contractile function significantly and activates ERK1/2 kinase with no effect on survival, while at higher micromolar concentrations $\mathrm{H}_{2} \mathrm{O}_{2}$ can stimulate apoptosis via JNK and p38 kinase [52].

ROS mediate the prohypertrophic signaling of alpha 1 adrenergic and angiotensin II pathways [83-87], by means of Ras thiol regulation [88]. In the heart, different signaling pathways involved in the modulation of cardiac hypertrophy, including protein kinase C (PKC), the MAPKs p38, JNK, apoptosis-signaling kinase 1 (ASK-1), and ERK1/2 [33], NF- $\kappa \mathrm{B}$, calcineurin, many tyrosine kinases, Akt, and Phosphatidyl-Inositol-3-Kinase (PI3K) [25-27, 89, 90], can be stimulated by ROS. Interestingly, $\mathrm{H}_{2} \mathrm{O}_{2}$ stimulates hypertrophy by activating PI $3 \mathrm{~K}$ in a time- and dose-dependent manner [91].

ROS can also stimulate myocardial fibrosis, thus contributing to myocardial remodeling [92, 93]: ROS can activate cardiac fibroblasts [94], regulate collagen synthesis [95], and activate posttranslationally matrix metalloproteases (MMPs) that are secreted in an inactive form [96].

Finally, ROS are able to regulate proteins of the excitationcontraction (EC) coupling machinery directly [97] (Figure 1). ROS oxidation of critical thiols on the RyR increases its open probability thus enhancing $\mathrm{Ca}^{2+}$ release, exacerbating $\mathrm{Ca}^{2+}$ overload and myocyte dysfunction [7, 98, 99]. ROS can also target sarcolemmal L-type $\mathrm{Ca}^{2+}$ channel, thus suppressing the $\mathrm{Ca}^{2+}$ current [100]. Additionally, they can blunt the activity of the sarcoplasmic reticulum $\mathrm{Ca}^{2+}$ ATPase (SERCA2), which plays an essential role in controlling $\mathrm{Ca}^{2+}$ cycling, with consequent myocytes dysfunction $[33,101]$. Interestingly, low expression of SERCA2a can be already found in myocytes hypertrophied after ROS treatment [33]. Activation of $\mathrm{Ca}^{2+}$-calmodulin-dependent protein kinase II (CaMKII) by ROS [102] is critically linked to remodeling of ionic homeostasis in various experimental hypertrophy models $[103,104]$ including familial hypertrophic cardiomyopathy [105]. In the myocardium, ROS can regulate the function of other important channels, including sodium channels, potassium channels, and ion exchangers, such as the $\mathrm{Na}^{+} / \mathrm{Ca}^{2+}$ exchanger (NCX) and $\mathrm{Na}^{+} / \mathrm{H}^{+}$exchanger type $1[33,106-110]$. Also, in HF ROS can contribute to cardiac dysfunction by lowering myofilaments $\mathrm{Ca}^{2+}$ sensitivity [111, $112]$.

\section{Antioxidant Therapeutics in Heart Failure}

10.1. Standard Heart Failure Therapy That Possess Antioxidant Properties. During the last decades, treatment of HF has changed more than one time, along with the progressing pathophysiological knowledge of the disease. It initially focused on hemodynamic control and unloading of the heart with vasodilators and diuretics. Then, the concept that the compensatory neurohormonal response was no longer considered beneficial but rather worsening heart failure introduced inhibitors of renin-angiotensin-aldosterone system, as well as $\beta$-blockers, now used as current therapeutics. Then treatments focused on muscle stimulation in the weakened heart, but these therapeutics were set aside due to their detrimental effects when used in the long term [113] as demonstrated by several clinical trials $[1,4,7,114-118]$. In the last years, implantable devices have had a remarkable impact on management of heart failure, since electrical devices controlled by microprocessors can deliver therapy, monitor disease, and prevent sudden cardiac death $[2,3$, 7]. Interestingly, it has to be acknowledged that standard HF therapy is based on many drugs that possess redox properties (Table 1) [43]. For instance, current treatments with ACE inhibitors and ATII receptor blockers (ARBs) can limit ROS deleterious signaling $[43,119]$. Indeed, ATII can induce hypertrophy via a $\mathrm{G} \alpha \mathrm{q}$ mediated pathway that involves ROS generation and ROS-associated activation of various downstream signals $[85,120]$. Consequently, in clinical practice, blockade of either ATII production or ATII binding to the AT1 receptor can prolong survival in patients. Notably, antioxidants that counteract ROS effects can also blunt ATII-induced hypertrophy [43, 86].

Spironolactone inhibits aldosterone actions, blunting the myocardial oxidant and profibrotic conditions that are a hallmark of HF. Indeed, aldosterone is able to activate NADPH oxidases, thus increasing ROS production [43, 121]. Similarly, correction of redox imbalance has been implicated in the therapeutic effects of eplerenone in $\operatorname{HF}[43,122,123]$.

Interestingly, recent studies on cardiac resynchronization therapy (CRT) demonstrate that the beneficial effects of this important device therapy also involve, among many, a redoxmechanism. In particular, in dyssynchronous HF, Cys294 of the mitochondrial F1-ATPase can form a disulfide bond with another cysteine residue, while introduction of CRT prevents disulfide formation with S-nitrosylation of Cys294 [124, 125]. 
TABLE 1: Properties of the main antioxidant therapeutics.

Components of standard heart failure therapy that possess antioxidant properties

ACEi, ARBs, ARNi, antialdosterone drugs: interference with RAAS signaling

Carvedilol: $\beta 1$ - and $\beta 2$-adrenergic receptor blocker that also increase NO production or decrease inactivation

$\beta 3 \mathrm{AR}$ agonists: enhancement of myocardial $\beta 3$-adrenergic coupling with NO-cGMP signaling

ARNi: enhancement of NPs/cGMP/PKG pathway

Drugs with redox effect that are not mainstream therapeutic approach in heart failure

PDE5 inhibition and BH4 supplementation: potentiating

NO/cGMP/PKG signaling

Statins: NADPH oxidase inhibitors

Allopurinol: xanthine oxidases inhibitor

Ranolazine: inhibitor of elevated late $\mathrm{I}_{\mathrm{Na}}$

MAO inhibitors: blunting ROS production from MAOs

Novel therapeutic compounds that target ROS/RNS signaling

pathways

SS-31 (MTP-131, Bendavia): direct action on mitochondrial function

Resveratrol: preservation of the LKB1-AMPK-eNOS signaling axis HNO donors: improving $\mathrm{Ca}^{2+}$ cycling and myofilament $\mathrm{Ca}^{2+}$ sensitivity

ARNi: angiotensin receptor-neprilysin inhibitor.

AMPK: AMP-activated protein kinase.

NPs: natriuretic peptides.

Carvedilol is $\beta 1$ - and $\beta 2$-adrenergic receptor antagonist with additional vasodilatory $\alpha 1$-blocking properties [126]. Its structure contains a carbazole moiety by which carvedilol can be considered also a potent antioxidant [126-128], as a result of increased NO production or decreased inactivation [126, 129].

The third-generation $\beta$-blocker nebivolol, by simultaneous stimulation of $\beta 3$-adrenergic receptor (AR), can enhance NO signaling which is often lost in HF because of the lower NO bioavailability. The eNOS-dependency of nebivolol beneficial effects beyond conventional beta blockers was demonstrated in experimental models of postMI and hypertrophy $[130,131]$. A recent study [132] also showed that microdomain-targeted enhancement of myocardial $\beta 3 \mathrm{AR} / \mathrm{NO}-\mathrm{cGMP}$ signaling may be responsible, at least in part, for $\beta 1$-adrenergic antagonist-mediated preservation of cardiac function in a volume-overloaded canine model. Additionally, the BEAT-HF trial (NCT01876433) is recently evaluating efficacy of oral treatment with a $\beta 3 \mathrm{AR}$ agonist in chronic HF, exploring also potential effects on diastolic function, symptoms, repolarization duration, and safety (Table 1).

10.2. Drugs with Redox Effect That Are Not Mainstream Therapeutic Approach to Heart Failure. Potentiating NO/cGMP signaling has provided beneficial effects on animal models of $\mathrm{HF}$ by means of phosphodiesterases 5 (PDE5) inhibition [133] and by BH4 supplementation [73]. cGMP/PKG
(cGMP-dependent protein kinase) pathway negatively controls stress-response signaling. cGMP is generated upon natriuretic peptide binding to its receptors coupled to particulate guanylyl cyclase or upon $\mathrm{NO}$ activation of soluble guanylyl cyclase. Importantly, cGMP controls the activities of phosphodiesterases (which in turn control cAMP and cGMP hydrolysis) and can then activate PKG. This important kinase phosphorylates $\mathrm{Ca}^{2+}$ channels, myosin phosphatase, RGS2 (which negatively regulates G-proteincoupled receptors), and IRAG (which modulates inositol1,4,5-trisphosphate-dependent $\mathrm{Ca}^{2+}$ signaling), troponin I, and phospholamban [134]. Enhancing cGMP/PKG signaling by inhibiting PDE5 seems to be able to attenuate and reverse cardiac hypertrophy induced by pressure overload [133] and blunt acute and chronic $\beta$-adrenergic stimulation and also protect against ischaemia-reperfusion injury and myocardial apoptosis induced by antitumoral agents [135-137]. Even though the first clinical trials with sildenafil in HF have been somehow disappointing, the concept that the cGMP pathway is a promising target to exploit has been corroborated by the recent results on the beneficial effects of neprilysin inhibition combined to ARBs [138].

Simvastatin (NADPH oxidase inhibitor) and allopurinol (xanthine oxidases inhibitor) both counteract oxidative stress and interfere with ROS-mediated hypertrophic signaling [139], blunting cardiac remodeling. In particular, statins can inhibit the isoprenylation and activation of Racl and other proteins of the Rho family, hence lowering NADPH oxidase activity $[43,140]$. Additionally, it seems that statins have direct antioxidant effects on lipids, and it has been shown that the oxidation of LDL, VLDL, and HDL can be inhibited by hydroxyl metabolites of atorvastatin [43, 141]. Also, both short- and long-term therapies with statins can benefit endothelial dysfunction [43]. Recent work from Andres and colleagues [142] showed that acute cardioprotective effects elicited by simvastatin involve the protein Parkin that stimulates mitophagy and prevents mevalonate accumulation. The xanthine oxidase inhibitor allopurinol is currently studied to improve remodeling after MI in diabetic patients (clinicaltrials.gov: NCT01052272) [139].

Enhanced myocytes $\left[\mathrm{Na}^{+}\right]_{\mathrm{i}}$ has been recently shown to lower mitochondrial $\mathrm{Ca}^{2+}$ uptake, increasing ROS production [110]. The same group was able to prevent such enhanced ROS generation with an inhibitor of the mitochondrial $\mathrm{Na}^{+} / \mathrm{Ca}^{2+}$ exchanger (mNCE), which decreased $\mathrm{Na}^{+}$-induced $\mathrm{Ca}^{2+}$ exportation [109]. In turn, ROS could then activate $\mathrm{Ca}^{2+} /$ calmoduline kinase II $[104,143]$ that would increase late $\mathrm{I}_{\mathrm{Na}}$ by interacting with the $\mathrm{Na}^{+}$channel $[144,145]$, thus generating a vicious cycle of high $\left[\mathrm{Na}^{+}\right]_{\mathrm{i}}$ and oxidative stress [110]. High $\left[\mathrm{Na}^{+}\right]_{\mathrm{i}}$ would then stimulate NCX and intracellular $\mathrm{Na}^{+}$would be exchanged with extracellular $\mathrm{Ca}^{2+}$ with consequent $\mathrm{Ca}^{2+}$ overload and electrical and mechanical dysfunction, in a scenario in which SERCA2a is inhibited and the RyR2 is activated by ROS [146, 147]. Hence, high $\left[\mathrm{Na}^{+}\right]_{\mathrm{i}}$ can be identified as an interesting therapeutic target for HF treatment [102]. Indeed, inhibiting the late $\mathrm{I}_{\mathrm{Na}}$ with ranolazine has been proven beneficial in experimental $\mathrm{HF}$ [102, 148-151]. 
Other promising therapeutic targets are monoaminoxidases: MAO A and MAO B have been recently proposed to play a role in experimental hypertrophy and failure via increased generation of $\mathrm{H}_{2} \mathrm{O}_{2}$. Pharmacological or genetic manipulation of such enzymes could then prove beneficial in cardiac dysfunction $[25,152,153]$ (Table 1$)$.

10.3. Novel Therapeutic Compounds That Target the ROS/RNS Signaling Pathways. Other interesting compounds that may ameliorate cardiac function by acting on the redox milieu have been identified. SS-31 (MTP-131, Bendavia) [154] is a mitochondria-specific antioxidant that appears to decrease LV hypertrophy in a mouse model of ATII-induced hypertrophy [155] and improve postinfarction cardiac function preventing adverse left ventricular remodeling and restoring mitochondria-related gene expression in rats [156]. Four phase I trials with Bendavia have been completed, with an ongoing phase II trial in ischaemic cardiomyopathy $[139,157]$.

Resveratrol is a widely used antioxidant dietary supplement with promising experimental results on pressure overload cardiac hypertrophy, but beneficial effects on clinical hypertrophy have not yet been reported $[139,158]$.

Currently, in $\mathrm{HF}$ treatment the room for inotropic therapies such as dopamine, dobutamine, and milrinone is very limited by the mortality associated with long-term treatment with these drugs [115-117]. Nitroxyl (HNO) represents an alternative approach. HNO is a 1-electron-reduced and protonated sibling of $\mathrm{NO}$ and, like $\mathrm{NO}$, is a gaseous signaling molecule and a potent vasodilator. Nevertheless, HNO appears to have distinct chemical and physiological properties and unique signaling pathways from those of $\mathrm{NO}$ $[159,160]$. HNO was initially discovered to induce both venous and arterial dilation and positive inotropy in intact failing hearts. Following mechanistic studies have revealed multiple pathways that combine the strategies of these other approaches. Clinical interest in $\mathrm{HNO}$ is increasing in virtue of its positive inotropic effects. In vitro experiments suggested positive inotropic and lusitropic properties of HNO, while subsequent studies in healthy and heart failure dog models with the $\mathrm{HNO}$ donor Angeli's salt $\left(\mathrm{Na}_{2} \mathrm{~N}_{2} \mathrm{O}_{3}\right)$ demonstrated significant improvements in load-independent LV contractility, associated with reductions in preload volume and diastolic pressure [161, 162]. These beneficial effects seem to be independent of cAMP/protein kinase A (PKA) and cGMP/PKG signaling [163] with no modification of L-type calcium channel activity [164], but rather related to modifications of specific cysteine residues on phospholamban $[165,166]$ and SERCA2a [167] and on myofilament proteins, correlating with increased $\mathrm{Ca}^{2+}$ sensitivity and force generation [168]. Recently, a new HNO donor, CXL-1020, has been developed, and both animal and clinical studies seem to confirm positive inotropic and lusitropic effects [118, 169-171] (Table 1).

\section{Conclusions}

ROS and RNS at physiological concentrations are beneficial molecules and play a role in the regulation of cellular signaling pathways [28]. ROS/RNS generation is finely regulated for proper myocardial homeostasis. Although oxidative and nitrosative stress can be deleterious and may therefore constitute a therapeutic target in HF, indiscriminate elimination of ROS and RNS by antioxidant treatments may not provide any improvement and may even impair physiological cellular functions, causing a complete loss of ROS/RNS signaling [172-175]. Indeed, antioxidants were shown to be able to counteract cardiac remodeling and improve contractility in many animal models of HF. However, when translated to the clinical arena, such therapeutic strategies [64] did not show the expected benefits or even worsened mortality [176], when the antioxidant effect was not paralleled by other pharmaceutical and biological properties, as for carvedilol [126]. Importantly, ROS biological effects on cardiomyocytes depend on the site of generation. Therefore, more specific, targeted, and "compartmentalized" antioxidant approaches that blunt local ROS/RNS production might be more successful in countering irreversible oxidative modifications. Furthermore, since in heart disease deranged mitochondria are the major generators of ROS, dictating the overall myocardial redox conditions, therapeutic strategies aimed at removing diseased mitochondria, thus promoting mitophagy, may help diminishing oxidative stress and ameliorating cardiac function [176].

\section{Conflict of Interests}

Carlo G. Tocchetti is a coinventor of the Canadian Patent no. 2,613,477: “Thiol Sensitive Positive Inotropes," issued on December 3, 2013.

\section{References}

[1] E. Braunwald, "The war against heart failure: the Lancet lecture," The Lancet, vol. 385, no. 9970, pp. 812-824, 2015.

[2] J. J. McMurray, S. Adamopoulos, S. D. Anker et al., "ESC Guidelines for the diagnosis and treatment of acute and chronic heart failure 2012: The Task Force for the Diagnosis and Treatment of Acute and Chronic Heart Failure 2012 of the European Society of Cardiology. Developed in collaboration with the Heart Failure Association (HFA) of the ESC," European Journal of Heart Failure, vol. 14, pp. 803-869, 2012.

[3] C. W. Yancy, M. Jessup, B. Bozkurt et al., "2013 ACCF/AHA guideline for the management of heart failure: a report of the American College of Cardiology Foundation/American Heart Association Task Force on Practice Guidelines," Circulation, vol. 128, no. 16, pp. e240-e327, 2013.

[4] G. Tarone, J.-L. Balligand, J. Bauersachs et al., "Targeting myocardial remodelling to develop novel therapies for heart failure: a position paper from the Working Group on Myocardial Function of the European Society of Cardiology," European Journal of Heart Failure, vol. 16, no. 5, pp. 494-508, 2014.

[5] A. S. Go, D. Mozaffarian, V. L. Roger et al., "Heart disease and stroke statistics-2014 update: a report from the American Heart Association," Circulation, vol. 129, no. 3, pp. e28-e292, 2014.

[6] S. J. Greene, G. C. Fonarow, M. Vaduganathan, S. S. Khan, J. Butler, and M. Gheorghiade, "The vulnerable phase after 
hospitalization for heart failure," Nature Reviews Cardiology, vol. 12, no. 4, pp. 220-229, 2015.

[7] J. O. Mudd and D. A. Kass, "Tackling heart failure in the twentyfirst century," Nature, vol. 451, no. 7181, pp. 919-928, 2008.

[8] J. N. Cohn, T. B. Levine, and M. T. Olivari, "Plasma norepinephrine as a guide to prognosis in patients with chronic congestive heart failure," The New England Journal of Medicine, vol. 311, no. 13, pp. 819-823, 1984.

[9] B. Pitt, F. Zannad, W. J. Remme et al., "The effect of spironolactone on morbidity and mortality in patients with severe heart failure," The New England Journal of Medicine, vol. 341, no. 10, pp. 709-717, 1999.

[10] M. A. Pfeffer, E. Braunwald, L. A. Moyé et al., "Effect of captopril on mortality and morbidity in patients with left ventricular dysfunction after myocardial infarction. Results of the Survival and Ventricular Enlargement Trial," The New England Journal of Medicine, vol. 327, no. 10, pp. 669-677, 1992.

[11] M. Packer, A. J. S. Coats, M. B. Fowler et al., "Effect of carvedilol on survival in severe chronic heart failure," The New England Journal of Medicine, vol. 344, no. 22, pp. 1651-1658, 2001.

[12] L. H. Opie and J. Knuuti, "The adrenergic-fatty acid load in heart failure," Journal of the American College of Cardiology, vol. 54, no. 18, pp. 1637-1646, 2009.

[13] L. Zhang, J. S. Jaswal, J. R. Ussher et al., "Cardiac insulin-resistance and decreased mitochondrial energy production precede the development of systolic heart failure after pressure-overload hypertrophy," Circulation: Heart Failure, vol. 6, no. 5, pp. 10391048, 2013.

[14] V. G. Dávila-Román, G. Vedala, P. Herrero et al., "Altered myocardial fatty acid and glucose metabolism in idiopathic dilated cardiomyopathy," Journal of the American College of Cardiology, vol. 40, no. 2, pp. 271-277, 2002.

[15] M. N. Sack, T. A. Rader, S. Park, J. Bastin, S. A. McCune, and D. P. Kelly, "Fatty acid oxidation enzyme gene expression is downregulated in the failing heart," Circulation, vol. 94, no. 11, pp. 2837-2842, 1996.

[16] J. J. Lehman and D. P. Kelly, "Gene regulatory mechanisms governing energy metabolism during cardiac hypertrophic growth," Heart Failure Reviews, vol. 7, no. 2, pp. 175-185, 2002.

[17] G. D. Lopaschuk, J. R. Ussher, C. D. L. Folmes, J. S. Jaswal, and W. C. Stanley, "Myocardial fatty acid metabolism in health and disease," Physiological Reviews, vol. 90, no. 1, pp. 207-258, 2010.

[18] L. Nascimben, J. S. Ingwall, B. H. Lorell et al., "Mechanisms for increased glycolysis in the hypertrophied rat heart," Hypertension, vol. 44, no. 5, pp. 662-667, 2004.

[19] M. Taha and G. D. Lopaschuk, "Alterations in energy metabolism in cardiomyopathies," Annals of Medicine, vol. 39, no. 8, pp. 594-607, 2007.

[20] M. Brownlee, "Biochemistry and molecular cell biology of diabetic complications," Nature, vol. 414, no. 6865, pp. 813-820, 2001.

[21] M. A. Aon, C. G. Tocchetti, N. Bhatt, N. Paolocci, and S. Cortassa, "Protective mechanisms of mitochondria and heart function in diabetes," Antioxidants \& Redox Signaling, vol. 22, no. 17, pp. 1563-1586, 2015.

[22] J. R. Burgoyne, S.-I. Oka, N. Ale-Agha, and P. Eaton, "Hydrogen peroxide sensing and signaling by protein kinases in the cardiovascular system," Antioxidants \& Redox Signaling, vol. 18, no. 9, pp. 1042-1052, 2013.

[23] R. G. Weiss, G. Gerstenblith, and P. A. Bottomley, "ATP flux through creatine kinase in the normal, stressed, and failing human heart," Proceedings of the National Academy of Sciences of the United States of America, vol. 102, no. 3, pp. 808-813, 2005.

[24] C. G. Tocchetti, V. Caceres, B. A. Stanley et al., "GSH or palmitate preserves mitochondrial energetic/redox balance, preventing mechanical dysfunction in metabolically challenged myocytes/hearts from type 2 diabetic mice," Diabetes, vol. 61, no. 12, pp. 3094-3105, 2012.

[25] C. Tocchetti, M. Molinaro, T. Angelone et al., "Nitroso-redox balance and modulation of basal myocardial function: an update from the Italian Society of Cardiovascular Research (SIRC)," Current Drug Targets, vol. 16, no. 8, pp. 895-903, 2015.

[26] E. Takimoto and D. A. Kass, "Role of oxidative stress in cardiac hypertrophy and remodeling," Hypertension, vol. 49, no. 2, pp. 241-248, 2007.

[27] C. Nediani, L. Raimondi, E. Borchi, and E. Cerbai, "Nitric oxide/reactive oxygen species generation and nitroso/redox imbalance in heart failure: from molecular mechanisms to therapeutic implications," Antioxidants and Redox Signaling, vol. 14, no. 2, pp. 289-331, 2011.

[28] M. T. Ziolo and D. M. Bers, "The real estate of NOS signaling: location, location, location," Circulation Research, vol. 92, no. 12, pp. 1279-1281, 2003.

[29] E. Ortona, P. Margutti, P. Matarrese, F. Franconi, and W. Malorni, "Redox state, cell death and autoimmune diseases: a gender perspective," Autoimmunity Reviews, vol. 7, no. 7, pp. 579-584, 2008.

[30] J. M. Hare and J. S. Stamler, "NO/redox disequilibrium in the failing heart and cardiovascular system," Journal of Clinical Investigation, vol. 115, no. 3, pp. 509-517, 2005.

[31] J. R. Burgoyne, H. Mongue-Din, P. Eaton, and A. M. Shah, "Redox signaling in cardiac physiology and pathology," Circulation Research, vol. 111, no. 8, pp. 1091-1106, 2012.

[32] D. B. Sawyer, D. A. Siwik, L. Xiao, D. R. Pimentel, K. Singh, and W. S. Colucci, "Role of oxidative stress in myocardial hypertrophy and failure," Journal of Molecular and Cellular Cardiology, vol. 34, no. 4, pp. 379-388, 2002.

[33] F. J. Giordano, "Oxygen, oxidative stress, hypoxia, and heart failure," The Journal of Clinical Investigation, vol. 115, no. 3, pp. 500-508, 2005.

[34] C. E. Murdoch, M. Zhang, A. C. Cave, and A. M. Shah, "NADPH oxidase-dependent redox signalling in cardiac hypertrophy, remodelling and failure," Cardiovascular Research, vol. 71, no. 2, pp. 208-215, 2006.

[35] C. X. C. Santos, N. Anilkumar, M. Zhang, A. C. Brewer, and A. M. Shah, "Redox signaling in cardiac myocytes," Free Radical Biology and Medicine, vol. 50, no. 7, pp. 777-793, 2011.

[36] M. Zhang, A. Perino, A. Ghigo, E. Hirsch, and A. M. Shah, "NADPH oxidases in heart failure: poachers or gamekeepers?" Antioxidants and Redox Signaling, vol. 18, no. 9, pp. 1024-1041, 2013.

[37] J. K. Bendall, A. C. Cave, C. Heymes, N. Gall, and A. M. Shah, "Pivotal role of a gp91phox-containing NADPH oxidase in angiotensin II-induced cardiac hypertrophy in mice," Circulation, vol. 105, no. 3, pp. 293-296, 2002.

[38] T. Ago, J. Kuroda, J. Pain, C. Fu, H. Li, and J. Sadoshima, "Upregulation of Nox 4 by hypertrophic stimuli promotes apoptosis and mitochondrial dysfunction in cardiac myocytes," Circulation Research, vol. 106, no. 7, pp. 1253-1264, 2010.

[39] Y. H. Looi, D. J. Grieve, A. Siva et al., "Involvement of Nox2 NADPH oxidase in adverse cardiac remodeling after myocardial infarction," Hypertension, vol. 51, no. 2, pp. 319-325, 2008. 
[40] J. A. Byrne, D. J. Grieve, J. K. Bendall et al., "Contrasting roles of NADPH oxidase isoforms in pressure-overload versus angiotensin II-induced cardiac hypertrophy," Circulation Research, vol. 93, no. 9, pp. 802-805, 2003.

[41] C. Heymes, J. K. Bendall, P. Ratajczak et al., "Increased myocardial NADPH oxidase activity in human heart failure," Journal of the American College of Cardiology, vol. 41, no. 12, pp. 2164-2171, 2003.

[42] C. Nediani, E. Borchi, C. Giordano et al., "NADPH oxidasedependent redox signaling in human heart failure: relationship between the left and right ventricle," Journal of Molecular and Cellular Cardiology, vol. 42, no. 4, pp. 826-834, 2007.

[43] J. M. Zimmet and J. M. Hare, "Nitroso-redox interactions in the cardiovascular system," Circulation, vol. 114, no. 14, pp. 1531$1544,2006$.

[44] K. M. Minhas, R. M. Saraiva, K. H. Schuleri et al., "Xanthine oxidoreductase inhibition causes reverse remodeling in rats with dilated cardiomyopathy," Circulation Research, vol. 98, no. 2, pp. 271-279, 2006.

[45] C. Doerries, K. Grote, D. Hilfiker-Kleiner et al., "Critical role of the NAD(P)H oxidase subunit $\mathrm{p} 47^{\text {phox }}$ for left ventricular remodeling/dysfunction and survival after myocardial infarction," Circulation Research, vol. 100, no. 6, pp. 894-903, 2007.

[46] W. F. Saavedra, N. Paolocci, M. E. St. John et al., "Imbalance between xanthine oxidase and nitric oxide synthase signaling pathways underlies mechanoenergetic uncoupling in the failing heart," Circulation Research, vol. 90, no. 3, pp. 297-304, 2002.

[47] L. B. Stull, M. K. Leppo, L. Szweda, W. D. Gao, and E. Marbán, "Chronic treatment with allopurinol boosts survival and cardiac contractility in murine postischemic cardiomyopathy," Circulation Research, vol. 95, no. 10, pp. 1005-1011, 2004.

[48] L. Zhao, B. M. Roche, J. L. Wessale et al., "Chronic xanthine oxidase inhibition following myocardial infarction in rabbits: effects of early versus delayed treatment," Life Sciences, vol. 82, no. 9-10, pp. 495-502, 2008.

[49] B. Halliwell and J. M. Gutteridge, Free Radicals in Biology and Medicine, Oxford University Press, Oxford, UK, 4th edition, 2007.

[50] Y. F. Pung, W. J. Sam, J. P. Hardwick et al., "The role of mitochondrial bioenergetics and reactive oxygen species in coronary collateral growth," The American Journal of Physiology-Heart and Circulatory Physiology, vol. 305, no. 9, pp. H1275-H1280, 2013.

[51] D. C. Wallace, W. Fan, and V. Procaccio, "Mitochondrial energetics and therapeutics," Annual Review of Pathology, vol. 5, pp. 297-348, 2010.

[52] S. H. Kwon, D. R. Pimentel, A. Remondino, D. B. Sawyer, and W. S. Colucci, " $\mathrm{H}_{2} \mathrm{O}_{2}$ regulates cardiac myocyte phenotype via concentration-dependent activation of distinct kinase pathways," Journal of Molecular and Cellular Cardiology, vol. 35, no. 6, pp. 615-621, 2003.

[53] K. M. Haizlip, N. Hiranandani, B. J. Biesiadecki, and P. M. L. Janssen, "Impact of hydroxyl radical-induced injury on calcium handling and myofilament sensitivity in isolated myocardium," Journal of Applied Physiology, vol. 113, no. 5, pp. 766-774, 2012.

[54] F. Tullio, C. Angotti, M.-G. Perrelli, C. Penna, and P. Pagliaro, "Redox balance and cardioprotection," Basic Research in Cardiology, vol. 108, no. 6, article 392, 2013.

[55] T. Ide, H. Tsutsui, S. Kinugawa et al., "Mitochondrial electron transport complex I is a potential source of oxygen free radicals in the failing myocardium," Circulation Research, vol. 85, no. 4, pp. 357-363, 1999.
[56] T. Ide, H. Tsutsui, S. Kinugawa et al., "Direct evidence for increased hydroxyl radicals originating from superoxide in the failing myocardium," Circulation Research, vol. 86, no. 2, pp. 152-157, 2000.

[57] N. Kaludercic, J. Mialet-Perez, N. Paolocci, A. Parini, and F. Di Lisa, "Monoamine oxidases as sources of oxidants in the heart," Journal of Molecular and Cellular Cardiology, vol. 73, pp. 34-42, 2014.

[58] G. Agati, E. Azzarello, S. Pollastri, and M. Tattini, "Flavonoids as antioxidants in plants: location and functional significance," Plant Science, vol. 196, pp. 67-76, 2012.

[59] M. Rizwan, I. Rodriguez-Blanco, A. Harbottle, M. A. BirchMachin, R. E. B. Watson, and L. E. Rhodes, "Tomato paste rich in lycopene protects against cutaneous photodamage in humans in vivo: a randomized controlled trial," British Journal of Dermatology, vol. 164, no. 1, pp. 154-162, 2011.

[60] C. Nathan, "Inducible nitric oxide synthase: what difference does it make?" Journal of Clinical Investigation, vol. 100, no. 10, pp. 2417-2423, 1997.

[61] L. A. Barouch, R. W. Harrison, M. W. Skaf et al., "Nitric oxide regulates the heart by spatial confinement of nitric oxide synthase isoforms," Nature, vol. 416, no. 6878, pp. 337-340, 2002.

[62] P. B. Massion, O. Feron, C. Dessy, and J.-L. Balligand, "Nitric oxide and cardiac function: ten years after, and continuing," Circulation Research, vol. 93, no. 5, pp. 388-398, 2003.

[63] C. E. Sears, E. A. Ashley, and B. Casadei, "Nitric oxide control of cardiac function: is neuronal nitric oxide synthase a key component?" Philosophical Transactions of the Royal Society B: Biological Sciences, vol. 359, no. 1446, pp. 1021-1044, 2004.

[64] C. G. Tocchetti, B. A. Stanley, C. I. Murray et al., "Playing with cardiac 'redox switches': the 'HNO' way to modulate cardiac function," Antioxidants \& Redox Signaling, vol. 14, no. 9, pp. 1687-1698, 2011.

[65] O. Feron, C. Dessy, D. J. Opel, M. A. Arstall, R. A. Kelly, and T. Michel, "Modulation of the endothelial nitric-oxide synthase-caveolin interaction in cardiac myocytes: implications for the autonomic regulation of heart rate," Journal of Biological Chemistry, vol. 273, no. 46, pp. 30249-30254, 1998.

[66] J. M. Hare, R. A. Lofthouse, G. J. Juang et al., "Contribution of caveolin protein abundance to augmented nitric oxide signaling in conscious dogs with pacing-induced heart failure," Circulation Research, vol. 86, no. 10, pp. 1085-1092, 2000.

[67] P. M. Hassoun, F. S. Yu, J. J. Zulueta, A. C. White, and J. J. Lanzillo, "Effect of nitric oxide and cell redox status on the regulation of endothelial cell xanthine dehydrogenase," American Journal of Physiology: Lung Cellular and Molecular Physiology, vol. 268, no. 5, pp. L809-L817, 1995.

[68] C. G. Cote, F.-S. Yu, J. J. Zulueta, R. J. Vosatka, and P. M. Hassoun, "Regulation of intracellular xanthine oxidase by endothelial-derived nitric oxide," American Journal of Physiology-Lung Cellular and Molecular Physiology, vol. 271, no. 5, pp. 869-874, 1996.

[69] E. Takimoto, H. C. Champion, M. Li et al., "Oxidant stress from nitric oxide synthase-3 uncoupling stimulates cardiac pathologic remodeling from chronic pressure load," The Journal of Clinical Investigation, vol. 115, no. 5, pp. 1221-1231, 2005.

[70] C.-A. Chen, C.-H. Lin, L. J. Druhan, T.-Y. Wang, Y.-R. Chen, and J. L. Zweier, "Superoxide induces endothelial nitric-oxide synthase protein thiyl radical formation, a novel mechanism regulating eNOS function and coupling," The Journal of Biological Chemistry, vol. 286, no. 33, pp. 29098-29107, 2011. 
[71] J. K. Bendall, N. J. Alp, N. Warrick et al., "Stoichiometric relationships between endothelial tetrahydrobiopterin, eNOS activity and eNOS coupling in vivo: insights from transgenic mice with endothelial-targeted GTPCH and eNOS over-expression," Circulation Research, vol. 97, no. 9, pp. 864-871, 2005.

[72] L. M. Bevers, B. Braam, J. A. Post et al., "Tetrahydrobiopterin, but not L-arginine, decreases NO synthase uncoupling in cells expressing high levels of endothelial NO synthase," Hypertension, vol. 47, no. 1, pp. 87-94, 2006.

[73] A. L. Moens, E. Takimoto, C. G. Tocchetti et al., "Reversal of cardiac hypertrophy and fibrosis from pressure overload by tetrahydrobiopterin: efficacy of recoupling nitric oxide synthase as a therapeutic strategy," Circulation, vol. 117, no. 20, pp. 26262636, 2008.

[74] N. Paolocci, R. Biondi, M. Bettini et al., "Oxygen radicalmediated reduction in basal and agonist-evoked no release in isolated rat heart," Journal of Molecular and Cellular Cardiology, vol. 33, no. 4, pp. 671-679, 2001.

[75] B. M. Gaston, J. Carver, A. Doctor, and L. A. Palmer, "Snitrosylation signaling in cell biology," Molecular Interventions, vol. 3, no. 5, pp. 253-263, 2003.

[76] M. T. Ziolo and S. R. Houser, "Abnormal $\mathrm{Ca}^{2+}$ cycling in failing ventricular myocytes: role of NOS1-mediated nitrosoredox balance," Antioxidants and Redox Signaling, vol. 21, no. 14, pp. 2044-2059, 2014.

[77] A. J. Lokuta, N. A. Maertz, S. V. Meethal et al., "Increased nitration of sarcoplasmic reticulum $\mathrm{Ca}^{2+}$-ATPase in human heart failure," Circulation, vol. 111, no. 8, pp. 988-995, 2005.

[78] T. Katori, S. Donzelli, C. G. Tocchetti et al., "Peroxynitrite and myocardial contractility: in vivo versus in vitro effects," Free Radical Biology and Medicine, vol. 41, no. 10, pp. 1606-1618, 2006.

[79] J. Sun, E. Picht, K. S. Ginsburg, D. M. Bers, C. Steenbergen, and E. Murphy, "Hypercontractile female hearts exhibit increased Snitrosylation of the L-type $\mathrm{Ca}^{2+}$ channel $\alpha 1$ subunit and reduced ischemia/reperfusion injury," Circulation Research, vol. 98, no. 3, pp. 403-411, 2006.

[80] T. M. Sarkela, J. Berthiaume, S. Elfering, A. A. Gybina, and C. Giulivi, "The modulation of oxygen radical production by nitric oxide in mitochondria," The Journal of Biological Chemistry, vol. 276, no. 10, pp. 6945-6949, 2001.

[81] P. Ježek and L. Hlavatá, "Mitochondria in homeostasis of reactive oxygen species in cell, tissues, and organism," International Journal of Biochemistry and Cell Biology, vol. 37, no. 12, pp. 24782503, 2005.

[82] D. Cesselli, I. Jakoniuk, L. Barlucchi et al., "Oxidative stressmediated cardiac cell death is a major determinant of ventricular dysfunction and failure in dog dilated cardiomyopathy," Circulation Research, vol. 89, no. 3, pp. 279-286, 2001.

[83] L. Xiao, D. R. Pimental, J. K. Amin, K. Singh, D. B. Sawyer, and W. S. Colucci, "MEK1/2-ERK1/2 mediates $\alpha_{1}$-adrenergic receptor-stimulated hypertrophy in adult rat ventricular myocytes," Journal of Molecular and Cellular Cardiology, vol. 33, no. 4, pp. 779-787, 2001.

[84] K. Tanaka, M. Honda, and T. Takabatake, "Redox regulation of MAPK pathways and cardiac hypertrophy in adult rat cardiac myocyte," Journal of the American College of Cardiology, vol. 37, no. 2, pp. 676-685, 2001.

[85] K. Nakamura, K. Fushimi, H. Kouchi et al., "Inhibitory effects of antioxidants on neonatal rat cardiac myocyte hypertrophy induced by tumor necrosis factor-alpha and angiotensin II," Circulation, vol. 98, no. 8, pp. 794-799, 1998.
[86] S. Delbosc, J.-P. Cristol, B. Descomps, A. Mimran, and B. Jover, "Simvastatin prevents angiotensin II-induced cardiac alteration and oxidative stress," Hypertension, vol. 40, no. 2, pp. 142-147, 2002.

[87] J. K. Amin, L. Xiao, D. R. Pimental et al., "Reactive oxygen species mediate alpha-adrenergic receptor-stimulated hypertrophy in adult rat ventricular myocytes," Journal of Molecular and Cellular Cardiology, vol. 33, no. 1, pp. 131-139, 2001.

[88] G. M. Kuster, D. R. Pimentel, T. Adachi et al., " $\alpha$-adrenergic receptor-stimulated hypertrophy in adult rat ventricular myocytes is mediated via thioredoxin-1-sensitive oxidative modification of thiols on ras," Circulation, vol. 111, no. 9, pp. 1192-1198, 2005.

[89] A. Sabri, H. H. Hughie, and P. A. Lucchesi, "Regulation of hypertrophic and apoptotic signaling pathways by reactive oxygen species in cardiac myocytes," Antioxidants and Redox Signaling, vol. 5, no. 6, pp. 731-740, 2003.

[90] I. Kehat and J. D. Molkentin, "Molecular pathways underlying cardiac remodeling during pathophysiological stimulation," Circulation, vol. 122, no. 25, pp. 2727-2735, 2010.

[91] V. C. Tu, J. J. Bahl, and Q. M. Chen, "Signals of oxidant-induced cardiomyocyte hypertrophy: key activation of p70 S6 kinase-1 and phosphoinositide 3-kinase," Journal of Pharmacology and Experimental Therapeutics, vol. 300, no. 3, pp. 1101-1110, 2002.

[92] D. Sorescu and K. K. Griendling, "Reactive oxygen species, mitochondria, and NAD $(\mathrm{P}) \mathrm{H}$ oxidases in the development and progression of heart failure," Congestive Heart Failure, vol. 8, no. 3, pp. 132-140, 2002.

[93] F. G. Spinale, "Bioactive peptide signaling within the myocardial interstitium and the matrix metalloproteinases," Circulation Research, vol. 91, no. 12, pp. 1082-1084, 2002.

[94] T.-H. Cheng, P.-Y. Cheng, N.-L. Shih, I.-B. Chen, D. L. Wang, and J.-J. Chen, "Involvement of reactive oxygen species in angiotensin II-induced endothelin-1 gene expression in rat cardiac fibroblasts," Journal of the American College of Cardiology, vol. 42, no. 10, pp. 1845-1854, 2003.

[95] D. A. Siwik, P. J. Pagano, and W. S. Colucci, “Oxidative stress regulates collagen synthesis and matrix metalloproteinase activity in cardiac fibroblasts," American Journal of Physiology: Cell Physiology, vol. 280, no. 1, pp. C53-C60, 2001.

[96] D. A. Siwik and W. S. Colucci, "Regulation of matrix metalloproteinases by cytokines and reactive oxygen/nitrogen species in the myocardium," Heart Failure Reviews, vol. 9, no. 1, pp. 4351, 2004.

[97] D. M. Bers, "Altered cardiac myocyte Ca regulation in heart failure," Physiology, vol. 21, no. 6, pp. 380-387, 2006.

[98] A. V. Zima and L. A. Blatter, "Redox regulation of cardiac calcium channels and transporters," Cardiovascular Research, vol. 71, no. 2, pp. 310-321, 2006.

[99] K. Y. Xu, J. L. Zweier, and L. C. Becker, "Hydroxyl radical inhibits sarcoplasmic reticulum $\mathrm{Ca}^{2+}$-ATPase function by direct attack on the ATP binding site," Circulation Research, vol. 80, no. 1, pp. 76-81, 1997.

[100] L. Guerra, E. Cerbai, S. Gessi, P. A. Borea, and A. Mugelli, "The effect of oxygen free radicals on calcium current and dihydropyridine binding sites in guinea-pig ventricular myocytes," British Journal of Pharmacology, vol. 118, no. 5, pp. 1278-1284, 1996.

[101] P. Kaplan, E. Babusikova, J. Lehotsky, and D. Dobrota, "Free radical-induced protein modification and inhibition of $\mathrm{Ca}^{2+}$ ATPase of cardiac sarcoplasmic reticulum," Molecular and Cellular Biochemistry, vol. 248, no. 1-2, pp. 41-47, 2003. 
[102] C. G. Tocchetti, A. Carpi, C. Coppola et al., "Ranolazine protects from doxorubicin-induced oxidative stress and cardiac dysfunction," European Journal of Heart Failure, vol. 16, no. 4, pp. 358-366, 2014.

[103] R. Zhang, M. S. C. Khoo, Y. Wu et al., "Calmodulin kinase II inhibition protects against structural heart disease," Nature Medicine, vol. 11, no. 4, pp. 409-417, 2005.

[104] J. R. Erickson, M.-L. A. Joiner, X. Guan et al., "A dynamic pathway for calcium-independent activation of CaMKII by methionine oxidation," Cell, vol. 133, no. 3, pp. 462-474, 2008.

[105] R. Coppini, C. Ferrantini, L. Yao et al., "Late sodium current inhibition reverses electromechanical dysfunction in human hypertrophic cardiomyopathy," Circulation, vol. 127, no. 5, pp. 575-584, 2013.

[106] H. Nakaya, Y. Takeda, N. Tohse, and M. Kanno, "Mechanism of the membrane depolarization induced by oxidative stress in guinea-pig ventricular cells," Journal of Molecular and Cellular Cardiology, vol. 24, no. 5, pp. 523-534, 1992.

[107] J. I. Goldhaber, "Free radicals enhance $\mathrm{Na}+/ \mathrm{Ca} 2+$ exchange in ventricular myocytes," American Journal of Physiology Heart and Circulatory Physiology, vol. 271, no. 3, pp. H823-H833, 1996.

[108] B. Pieske and S. R. Houser, " $\left[\mathrm{Na}^{+}\right]_{\mathrm{i}}$ handling in the failing human heart," Cardiovascular Research, vol. 57, pp. 874-886, 2003.

[109] C. Maack, S. Cortassa, M. A. Aon, A. N. Ganesan, T. Liu, and B. O'Rourke, "Elevated cytosolic $\mathrm{Na}^{+}$decreases mitochondrial $\mathrm{Ca}^{2+}$ uptake during excitation-contraction coupling and impairs energetic adaptation in cardiac myocytes," Circulation Research, vol. 99, no. 2, pp. 172-182, 2006.

[110] M. Kohlhaas, T. Liu, A. Knopp et al., "Elevated cytosolic $\mathrm{Na}^{+}$ increases mitochondrial formation of reactive oxygen species in failing cardiac myocytes," Circulation, vol. 121, no. 14, pp. 1606$1613,2010$.

[111] M. Canton, A. Skyschally, R. Menabò et al., "Oxidative modification of tropomyosin and myocardial dysfunction following coronary microembolization," European Heart Journal, vol. 27, no. 7, pp. 875-881, 2006.

[112] M. Canton, S. Menazza, F. L. Sheeran, P. Polverino De Laureto, F. Di Lisa, and S. Pepe, "Oxidation of myofibrillar proteins in human heart failure," Journal of the American College of Cardiology, vol. 57, no. 3, pp. 300-309, 2011.

[113] M. Packer, J. R. Carver, R. J. Rodeheffer et al., "Effect of oral milrinone on mortality in severe chronic heart failure. The PROMISE Study Research Group," The New England Journal of Medicine, vol. 325, no. 21, pp. 1468-1475, 1991.

[114] D. L. Mann and M. R. Bristow, "Mechanisms and models in heart failure: the biomechanical model and beyond," Circulation, vol. 111, no. 21, pp. 2837-2849, 2005.

[115] J. I. Goldhaber and M. A. Hamilton, "Role of inotropic agents in the treatment of heart failure," Circulation, vol. 121, no. 14, pp. 1655-1660, 2010.

[116] G. Hasenfuss and J. R. Teerlink, "Cardiac inotropes: current agents and future directions," European Heart Journal, vol. 32, no. 15, pp. 1838-1845, 2011.

[117] L. Nagy, P. Pollesello, and Z. Papp, "Inotropes and inodilators for acute heart failure: sarcomere active drugs in focus," Journal of Cardiovascular Pharmacology, vol. 64, no. 3, pp. 199-208, 2014.

[118] A. Arcaro, G. Lembo, and C. G. Tocchetti, "Nitroxyl (HNO) for treatment of acute heart failure," Current Heart Failure Reports, vol. 11, no. 3, pp. 227-235, 2014.
[119] N. Khaper and P. K. Singal, "Modulation of oxidative stress by a selective inhibition of angiotensin II type 1 receptors in MI rats," Journal of the American College of Cardiology, vol. 37, no. 5, pp. 1461-1466, 2001.

[120] F. Stillitano, L. Sartiani, P. DePaoli, A. Mugelli, and E. Cerbai, "Expression of the hyperpolarization-activated current, $I_{\mathrm{f}}$, in cultured adult rat ventricular cardiomyocytes and its modulation by hypertrophic factors," Pharmacological Research, vol. 57, no. 2, pp. 100-109, 2008.

[121] K. Miyata, M. Rahman, T. Shokoji et al., "Aldosterone stimulates reactive oxygen species production through activation of NADPH oxidase in rat mesangial cells," Journal of the American Society of Nephrology, vol. 16, no. 10, pp. 2906-2912, 2005.

[122] D. Sanz-Rosa, M. P. Oubiña, E. Cediel et al., "Eplerenone reduces oxidative stress and enhances eNOS in SHR: vascular functional and structural consequences," Antioxidants and Redox Signaling, vol. 7, no. 9-10, pp. 1294-1301, 2005.

[123] F. Zannad, J. J. V. McMurray, H. Krum et al., "Eplerenone in patients with systolic heart failure and mild symptoms," The New England Journal of Medicine, vol. 364, no. 1, pp. 11-21, 2011.

[124] S.-B. Wang, D. B. Foster, J. Rucker, B. O’Rourke, D. A. Kass, and J. E. Van Eyk, "Redox regulation of mitochondrial ATP synthase: implications for cardiac resynchronization therapy," Circulation Research, vol. 109, no. 7, pp. 750-757, 2011.

[125] G. Tong, A. M. Aponte, M. J. Kohr, C. Steenbergen, E. Murphy, and J. Sun, "Postconditioning leads to an increase in protein S-nitrosylation," American Journal of Physiology: Heart and Circulatory Physiology, vol. 306, no. 6, pp. H825-H832, 2014.

[126] G. C. Fonarow, "Role of carvedilol controlled-release in cardiovascular disease," Expert Review of Cardiovascular Therapy, vol. 7, no. 5, pp. 483-498, 2009.

[127] W. M. Book, "Carvedilol: a nonselective $\beta$ blocking agent with antioxidant properties," Congestive Heart Failure, vol. 8, no. 3, pp. 173-190, 2002.

[128] T. L. Yue, P. J. Mckenna, J. L. Gu, H. Y. Cheng, R. R. Ruffolo Jr., and G. Z. Feuerstein, "Carvedilol, a new antihypertensive agent, prevents lipid peroxidation and oxidative injury to endothelial cells," Hypertension, vol. 22, no. 6, pp. 922-928, 1993.

[129] N. Toda, "Vasodilating $\beta$-adrenoceptor blockers as cardiovascular therapeutics," Pharmacology and Therapeutics, vol. 100, no. 3, pp. 215-234, 2003.

[130] S. A. Sorrentino, C. Doerries, C. Manes et al., "Nebivolol exerts beneficial effects on endothelial function, early endothelial progenitor cells, myocardial neovascularization, and left ventricular dysfunction early after myocardial infarction beyond conventional $\beta 1$-blockade," Journal of the American College of Cardiology, vol. 57, no. 5, pp. 601-611, 2011.

[131] I. Ozakca, E. Arioglu-Inan, H. Esfahani et al., "Nebivolol prevents desensitization of $\beta$-adrenoceptor signaling and induction of cardiac hypertrophy in response to isoprenaline beyond $\beta 1$-adrenoceptor blockage," The American Journal of Physiology-Heart and Circulatory Physiology, vol. 304, no. 9, pp. H1267-H1276, 2013.

[132] D. M. Trappanese, Y. Liu, R. C. McCormick et al., "Chronic $\beta 1$-adrenergic blockade enhances myocardial $\beta 3$-adrenergic coupling with nitric oxide-cGMP signaling in a canine model of chronic volume overload: new insight into mechanisms of cardiac benefit with selective $\beta 1$-blocker therapy," Basic Research in Cardiology, vol. 110, no. 1, article 456, 2015.

[133] E. Takimoto, H. C. Champion, M. Li et al., "Chronic inhibition of cyclic GMP phosphodiesterase 5A prevents and reverses 
cardiac hypertrophy," Nature Medicine, vol. 11, no. 2, pp. 214$222,2005$.

[134] F. Hofmann, R. Feil, T. Kleppisch, and J. Schlossmann, "Function of cGMP-dependent protein kinases as revealed by gene deletion," Physiological Reviews, vol. 86, no. 1, pp. 1-23, 2006.

[135] D. A. Kass, H. C. Champion, and J. A. Beavo, "Phosphodiesterase type 5: expanding roles in cardiovascular regulation," Circulation Research, vol. 101, no. 11, pp. 1084-1095, 2007.

[136] A. Das, D. Durrant, F. N. Salloum, L. Xi, and R. C. Kukreja, "PDE5 inhibitors as therapeutics for heart disease, diabetes and cancer," Pharmacology and Therapeutics, vol. 147, pp. 12-21, 2015.

[137] P. W. Fisher, F. Salloum, A. Das, H. Hyder, and R. C. Kukreja, "Phosphodiesterase-5 inhibition with sildenafil attenuates cardiomyocyte apoptosis and left ventricular dysfunction in a chronic model of doxorubicin cardiotoxicity," Circulation, vol. 111, no. 13, pp. 1601-1610, 2005.

[138] J. J. V. McMurray, M. Packer, A. S. Desai et al., "Angiotensinneprilysin inhibition versus enalapril in heart failure," The New England Journal of Medicine, vol. 371, no. 11, pp. 993-1004, 2014.

[139] E. Bisping, P. Wakula, M. Poteser, and F. R. Heinzel, “Targeting cardiac hypertrophy: toward a causal heart failure therapy," Journal of Cardiovascular Pharmacology, vol. 64, no. 4, pp. 293305, 2014.

[140] A. Cordle, J. Koenigsknecht-Talboo, B. Wilkinson, A. Limpert, and G. Landreth, "Mechanisms of statin-mediated inhibition of small G-protein function," The Journal of Biological Chemistry, vol. 280, no. 40, pp. 34202-34209, 2005.

[141] M. Aviram, M. Rosenblat, C. L. Bisgaier, and R. S. Newton, "Atorvastatin and gemfibrozil metabolites, but not the parent drugs, are potent antioxidants against lipoprotein oxidation," Atherosclerosis, vol. 138, no. 2, pp. 271-280, 1998.

[142] A. M. Andres, G. Hernandez, P. Lee et al., "Mitophagy is required for acute cardioprotection by simvastatin," Antioxidants \& Redox Signaling, vol. 21, no. 14, pp. 1960-1973, 2014.

[143] M. Luo and M. E. Anderson, "Mechanisms of altered $\mathrm{Ca}^{2+}$ handling in heart failure," Circulation Research, vol. 113, no. 6, pp. 690-708, 2013.

[144] Y. Song, J. C. Shryock, S. Wagner, L. S. Maier, and L. Belardinelli, "Blocking late sodium current reduces hydrogen peroxideinduced arrhythmogenic activity and contractile dysfunction," Journal of Pharmacology and Experimental Therapeutics, vol. 318, no. 1, pp. 214-222, 2006.

[145] S. Wagner, N. Dybkova, E. C. Rasenack et al., " $\mathrm{Ca}^{2+} /$ calmodulin-dependent protein kinase II regulates cardiac $\mathrm{Na}^{+}$channels," Journal of Clinical Investigation, vol. 116, no. 12, pp. 31273138, 2006.

[146] D. M. Bers, Excitation-Contraction Coupling and Cardiac Contractile Force, Kluwer Academic Publishers, Dordrecht, The Netherlands, 2nd edition, 2001.

[147] O. Zeitz, A. E. Maass, P. Van Nguyen et al., "Hydroxyl radicalinduced acute diastolic dysfunction is due to calcium overload via reverse-mode $\mathrm{Na}^{+}-\mathrm{Ca}^{2+}$ exchange," Circulation Research, vol. 90, no. 9, pp. 988-995, 2002.

[148] H. Hwang, J. M. Arcidi Jr., S. L. Hale et al., "Ranolazine as a cardioplegia additive improves recovery of diastolic function in isolated rat hearts," Circulation, vol. 120, no. 1, pp. S16-S21, 2009.

[149] Y. Wu, Y. Song, L. Belardinelli, and J. C. Shryock, "The late $\mathrm{Na}^{+}$current $\left(\mathrm{I}_{\mathrm{Na}}\right)$ inhibitor ranolazine attenuates effects of palmitoyl-L-carnitine to increase late $\mathrm{I}_{\mathrm{Na}}$ and cause ventricular diastolic dysfunction," Journal of Pharmacology and Experimental Therapeutics, vol. 330, no. 2, pp. 550-557, 2009.
[150] H. N. Sabbah, M. P. Chandler, T. Mishima et al., "Ranolazine, a partial fatty acid oxidation (pFOX) inhibitor, improves left ventricular function in dogs with chronic heart failure," Journal of Cardiac Failure, vol. 8, no. 6, pp. 416-422, 2002.

[151] S. Rastogi, V. G. Sharov, S. Mishra et al., "Ranolazine combined with enalapril or metoprolol prevents progressive LV dysfunction and remodeling in dogs with moderate heart failure," The American Journal of Physiology-Heart and Circulatory Physiology, vol. 295, no. 5, pp. H2149-H2155, 2008.

[152] N. Kaludercic, E. Takimoto, T. Nagayama et al., "Monoamine oxidase A-mediated enhanced catabolism of norepinephrine contributes to adverse remodeling and pump failure in hearts with pressure overload," Circulation Research, vol. 106, no. 1, pp. 193-202, 2010.

[153] N. Kaludercic, A. Carpi, T. Nagayama et al., "Monoamine oxidase B prompts mitochondrial and cardiac dysfunction in pressure overloaded hearts," Antioxidants \& Redox Signaling, vol. 20, no. 2, pp. 267-280, 2014.

[154] H. H. Szeto and A. V. Birk, "Serendipity and the discovery of novel compounds that restore mitochondrial plasticity," Clinical Pharmacology \& Therapeutics, vol. 96, no. 6, pp. 672-683, 2014.

[155] D.-F. Dai, T. Chen, H. Szeto et al., "Mitochondrial targeted antioxidant peptide ameliorates hypertensive cardiomyopathy," Journal of the American College of Cardiology, vol. 58, no. 1, pp. 73-82, 2011.

[156] W. Dai, J. Shi, R. C. Gupta, H. N. Sabbah, S. L. Hale, and R. A. Kloner, "Bendavia, a mitochondria-targeting peptide, improves postinfarction cardiac function, prevents adverse left ventricular remodeling, and restores mitochondria-related gene expression in rats," Journal of Cardiovascular Pharmacology, vol. 64, no. 6, pp. 543-553, 2014.

[157] A. K. Chakrabarti, K. Feeney, C. Abueg et al., "Rationale and design of the EMBRACE STEMI study: a phase 2a, randomized, double-blind, placebo-controlled trial to evaluate the safety, tolerability and efficacy of intravenous Bendavia on reperfusion injury in patients treated with standard therapy including primary percutaneous coronary intervention and stenting for ST-segment elevation myocardial infarction," American Heart Journal, vol. 165, no. 4, pp. 509.e7-514.e7, 2013.

[158] V. W. Dolinsky, S. Chakrabarti, T. J. Pereira et al., "Resveratrol preventshypertension and cardiac hypertrophy in hypertensive rats and mice," Biochimica et Biophysica Acta, vol. 1832, no. 10, pp. 1723-1733, 2013.

[159] J. C. Irvine, R. H. Ritchie, J. L. Favaloro, K. L. Andrews, R. E. Widdop, and B. K. Kemp-Harper, "Nitroxyl (HNO): the Cinderella of the nitric oxide story," Trends in Pharmacological Sciences, vol. 29, no. 12, pp. 601-608, 2008.

[160] N. Paolocci, M. I. Jackson, B. E. Lopez et al., “The pharmacology of nitroxyl (HNO) and its therapeutic potential: not just the Janus face of NO," Pharmacology \& Therapeutics, vol. 113, no. 2, pp. 442-458, 2007.

[161] N. Paolocci, W. F. Saavedra, K. M. Miranda et al., "Nitroxyl anion exerts redox-sensitive positive cardiac inotropy in vivo by calcitonin gene-related peptide signaling," Proceedings of the National Academy of Sciences of the United States of America, vol. 98, no. 18, pp. 10463-10468, 2001.

[162] N. Paolocci, T. Katori, H. C. Champion et al., "Positive inotropic and lusitropic effects of $\mathrm{HNO} / \mathrm{NO}$ - in failing hearts: independence from $\beta$-adrenergic signaling," Proceedings of the National Academy of Sciences of the United States of America, vol. 100, no. 9, pp. 5537-5542, 2003. 
[163] C. G. Tocchetti, W. Wang, J. P. Froehlich et al., "Nitroxyl improves cellular heart function by directly enhancing cardiac sarcoplasmic reticulum $\mathrm{Ca}^{2+}$ cycling," Circulation Research, vol. 100, no. 1, pp. 96-104, 2007.

[164] M. J. Kohr, N. Kaludercic, C. G. Tocchetti et al., "Nitroxyl enhances myocyte $\mathrm{Ca}^{2+}$ transients by exclusively targeting SR $\mathrm{Ca}^{2+}$-cycling," Frontiers in Bioscience, vol. 2, no. 2, pp. 614-626, 2010.

[165] J. P. Froehlich, J. E. Mahaney, G. Keceli et al., "Phospholamban thiols play a central role in activation of the cardiac muscle sarcoplasmic reticulum calcium pump by nitroxyl," Biochemistry, vol. 47, no. 50, pp. 13150-13152, 2008.

[166] V. Sivakumaran, B. A. Stanley, C. G. Tocchetti et al., "HNO Enhances SERCA2a activity and cardiomyocyte function by promoting redox-dependent phospholamban oligomerization," Antioxidants and Redox Signaling, vol. 19, no. 11, pp. 1185-1197, 2013.

[167] S. Lancel, J. Zhang, A. Evangelista et al., "Nitroxyl activates SERCA in cardiac myocytes via glutathiolation of cysteine 674," Circulation Research, vol. 104, no. 6, pp. 720-723, 2009.

[168] W. D. Gao, C. I. Murray, Y. Tian et al., "Nitroxyl-mediated disulfide bond formation between cardiac myofilament cysteines enhances contractile function," Circulation Research, vol. 111, no. 8, pp. 1002-1011, 2012.

[169] H. N. Sabbah, C. G. Tocchetti, M. Wang et al., "A novel approach for the acute treatment of heart failure," Circulation: Heart Failure, vol. 6, no. 6, pp. 1250-1258, 2013.

[170] L. Beckendorf and W. A. Linke, "Emerging importance of oxidative stress in regulating striated muscle elasticity," Journal of Muscle Research and Cell Motility, vol. 36, no. 1, pp. 25-36, 2015.

[171] M. Breitkreuz and N. Hamdani, "A change of heart: oxidative stress in governing muscle function?" Biophysical Reviews, vol. 7, no. 3, pp. 321-341, 2015.

[172] M. A. Aon, S. Cortassa, and B. O'Rourke, "Redox-optimized ROS balance: a unifying hypothesis," Biochimica et Biophysica Acta, vol. 1797, no. 6-7, pp. 865-877, 2010.

[173] S. Cortassa, B. O’Rourke, and M. A. Aon, “Redox-optimized ROS balance and the relationship between mitochondrial respiration and ROS," Biochimica et Biophysica Acta-Bioenergetics, vol. 1837, no. 2, pp. 287-295, 2014.

[174] A. Nickel, M. Kohlhaas, and C. Maack, "Mitochondrial reactive oxygen species production and elimination," Journal of Molecular and Cellular Cardiology, vol. 73, pp. 26-33, 2014.

[175] T. Münzel, T. Gori, J. F. Keaney, C. Maack, and A. Daiber, "Pathophysiological role of oxidative stress in systolic and diastolic heart failure and its therapeutic implications," European Heart Journal, vol. 36, no. 38, pp. 2555-2564, 2015.

[176] J. A. Kirk and N. Paolocci, "New redox-related arrows in the arsenal of cardiac disease treatment," Antioxidants and Redox Signaling, vol. 21, no. 14, pp. 1945-1948, 2014. 


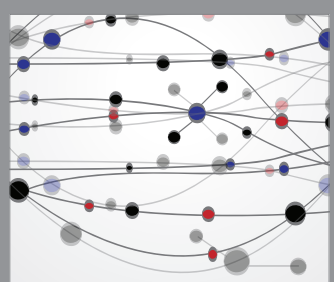

The Scientific World Journal
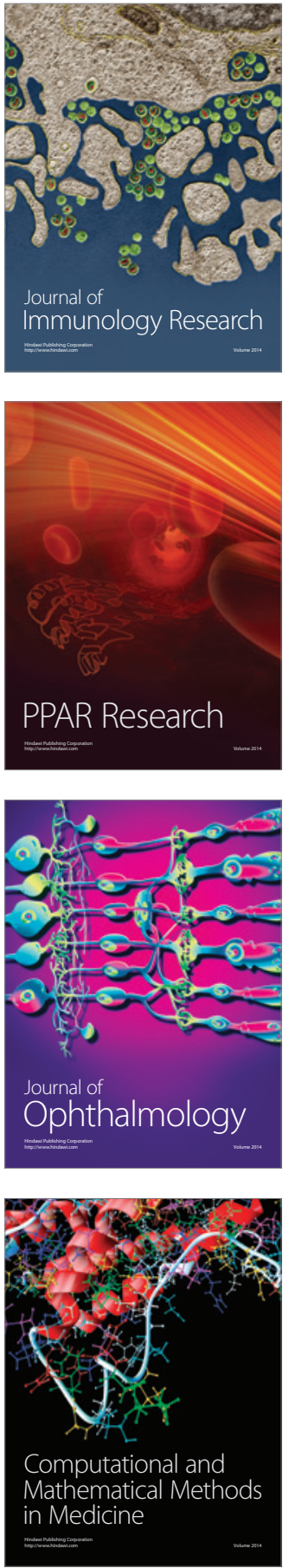

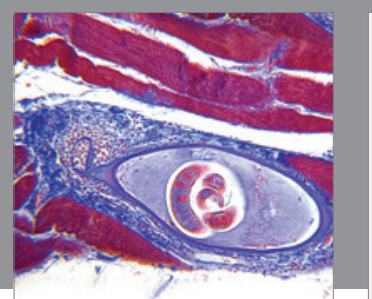

Gastroenterology Research and Practice

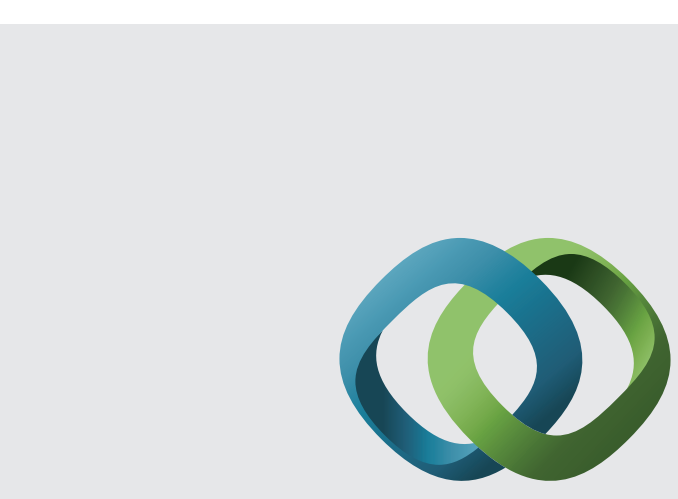

\section{Hindawi}

Submit your manuscripts at

http://www.hindawi.com
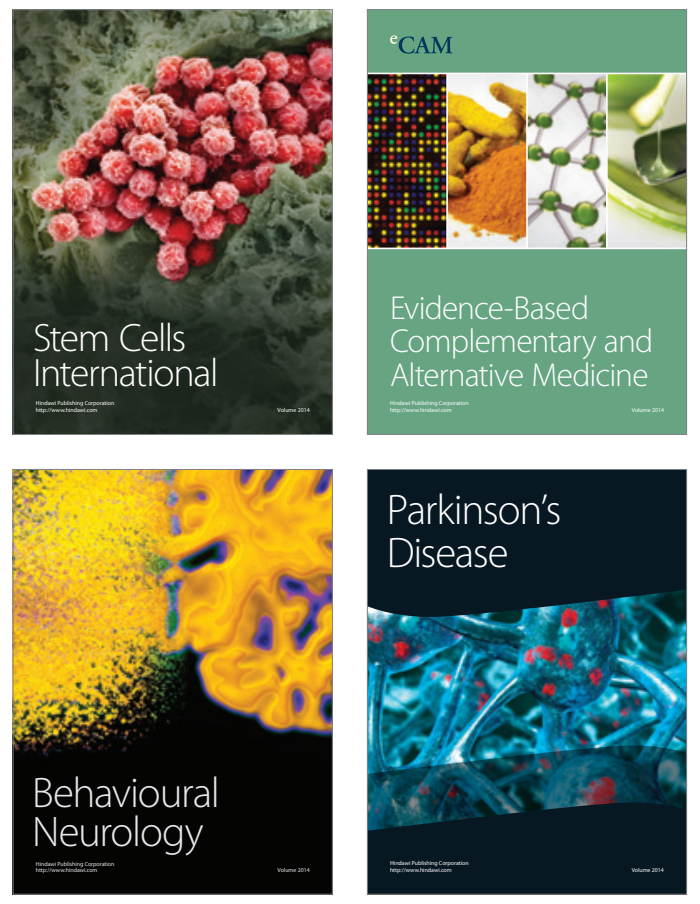
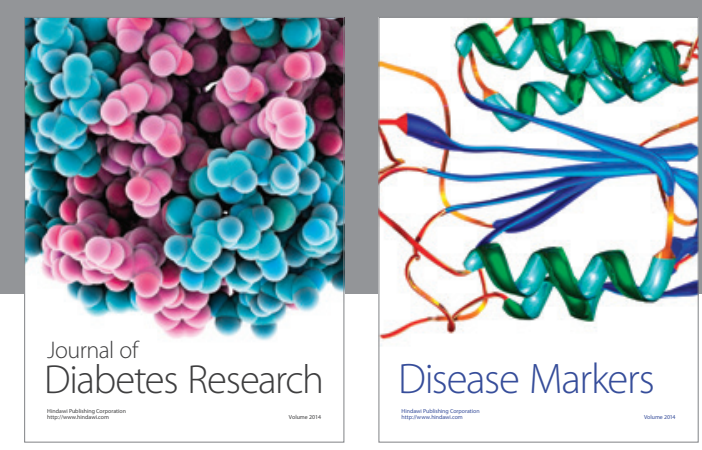

Disease Markers
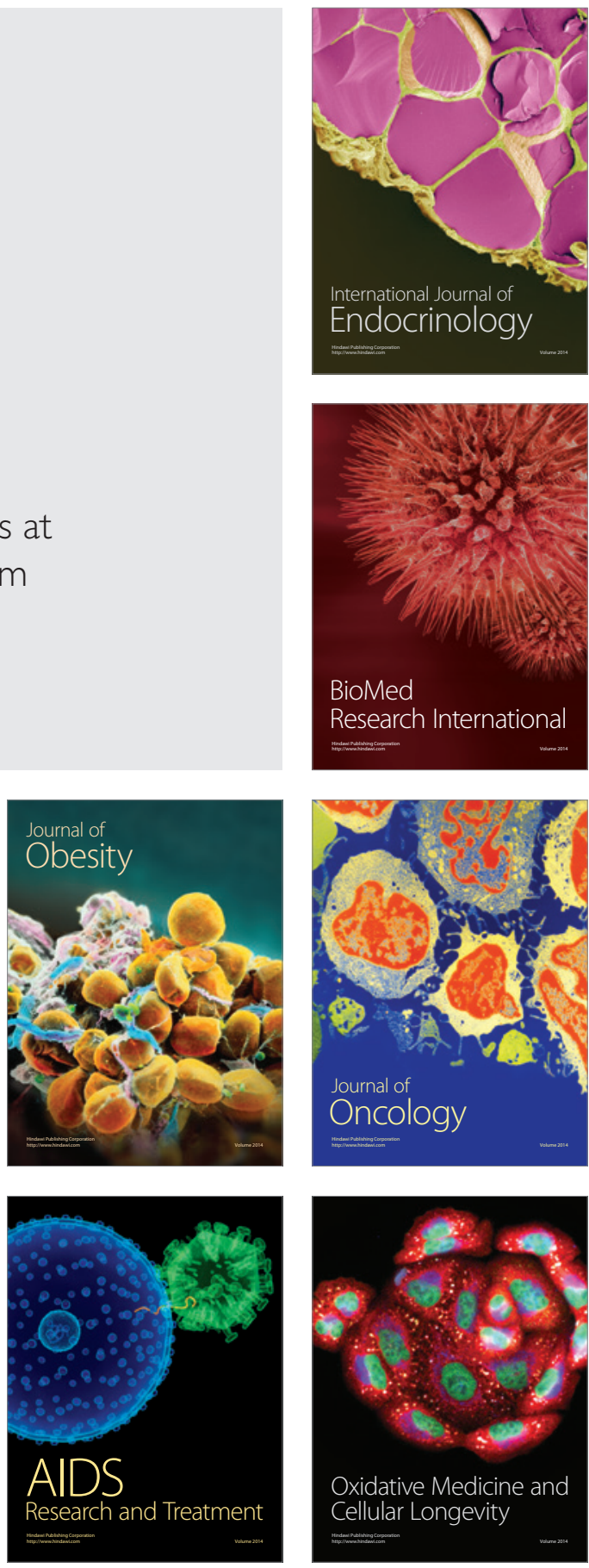